\title{
PENERAPAN SMART CAMPUS SEBAGAI PENDUKUNG KEGIATAN PENDIDIKAN DALAM TRI DHARMA PERGURUAN TINGGI
}

\author{
Muhammad Cordiaz \\ Teknik Informatika, Universitas Pamulang \\ email: dosen01676@unpam.ac.id
}

\begin{abstract}
ABSTRAK
Tantangan perguruan tinggi di era global adalah menghasilkan lulusan yang dapat beradaptasi dengan perkembangan jaman. Penyelenggaraan pendidikan dapat dilakukan dengan lebih modern dengan menerapkan teknologi yang terdapat dalam konsep smart campus. Penerapan teknologi smart campus membutuhkan waktu dan dana yang besar. Keuntungnya, teknologi smart campus dapat diterapkan bertahap. Pendidikan sebagai salah satu tanggungan jawab dalam Tri Dharma Perguruan Tinggi dapate menerapkan teknologi smart campus dalam bentuk jaringan wifi yang memadai, e-learning yang memanfaatkan aplikasi mobile dan web conference untuk presentasi online dan mata kuliah praktek.
\end{abstract}

Keywords: smart campus, e-learning, wifi, aplikasi mobile, web conference

\section{PENDAHULUAN}

Smart campus atau kampus cerdas, mengacu pada fasilitas-fasilitas kampus pendukung semua kegiatan sivitas akademika dalam melaksanakan kewajiban Tri Dharma Perguruan Tinggi yang menggunakan teknologi informasi sebagai tulang punggung pendukung. Smart campus dalam implementasinya tidak mudah karena melibatkan banyak sarana yang mesti diwujudkan. Implementasi teknologi smart campus secara miniatur akhirnya muncul, seperti smart class room, smart laboratory, smart building, smart department atau smart faculty (Dharma Putra, 2017).

Penerapan smart campus diperlukan sebagai perkembangan dari keadaan pengelolaan kampus konvensional atau yang biasa kemudian beralih ke dengan menerapkan sistem menggunakan teknologi. Kampus yang berkembang baik mampu mengimplementasikan kewajiban Tri Dharma Perguruan Tinggi sebagai tanggung jawab terhadap keilmuan, masyarakat dan lingkungannya. Kewajiban Tri Dharma Perguruan Tinggi memiliki domain penyelenggaraan pendidikan, penelitian dan pengabdian pada masyarakat.

Salah satu domainnya Tri Dharma Perguruan Tinggi yang mungkin ditingkatkan dalam pelayanan dan efisiensi menggunakan teknologi dalam lingkungan smart campus adalah domain pendidikan. Penerapan sistem teknologi dalam pengelolaan bidang pendidikan akan meningkatkan efisiensi dan kepuasan pemangku kepentingan. Pendidikan adalah usaha sadar dan terencana untuk mewujudkan suasana belajar dan proses pembelajaran agar peserta didik secara aktif mengembangkan potensi dirinya untuk memiliki kekuatan spiritual keagamaan, pengendalian diri, kepribadian, kecerdasan, akhlak mulia, serta keterampilan yang diperlukan dirinya, masyarakat, bangsa dan negara (Wibawa, 2017).

Pada beberapa universitas di luar negeri, konsep teknologi pada smart campus atau kampus cerdas diharapkan mampu mendukung proses pembelajaran tingkat lanjut dan riset juga untuk mengefisiensikan proses pengiriman layanan administrasi. Universitas yang menerapkan konsep teknologi ini contohnya Dalhousie University. Penerapan teknologi smart campus terutama untuk peningkatan kepuasan layanan dan faktor efisiensi.

Tujuan tulisan ini adalah untuk peningkatan layanan pendidikan sebagai salah satu kewajiban perguruan tinggi dalam menyelenggarakan Tri Dharma Perguruan Tinggi dengan menerapkan aspek-aspek teknologi yang terkandung dalam smart campus. Metode penelitian yang digunakan dalam penulisan ini adalah metode studi pustaka. Studi pustaka termasuk dalam penelitian deskriptif. Penelitian deskriptif mencoba mencari deskripsi yang tepat dan cukup dari semua aktivitas, objek, proses dan manusia (Sulistyo, 2010). Studi pustaka merupakan metode pengumpulan data dan informasi melalui dokumen-dokumen, baik dokumen tertulis, foto, gambar, maupun dokumen elektronik yang dapat mendukung dalam proses penulisan.

Objek penelitian ini adalah aspek-aspek dalam teknologi smart campus yang dapat diterapkan dalam proses penyelenggaraan 
pendidikan dan pengajaran sebagai kewajiban perguruan tinggi dalam Tri Dharma Perguruan Tinggi.

\section{METODE PENELITIAN}

Berdasarkan pendahuluan yang telah disampaikan dan sifat masalah yang akan dipecahkan, penelitian bersifat deskriptif. Penelitian deskriptif bertujuan untuk membuat deskripsi secara sistematis, faktual dan akurat mengenai fakta-fakta dan sifat populasi di wilayah tertentu (Suryana, 2010).

Menurut Rusidi (1991), berdasarkan tujuannya, penelitian deskriptif bertujuan untuk mengetahui perkembangan sarana fisik tertentu atau frekuensi terjadinya sesuatu aspek fenomena tertentu, dan untuk mendeskripsikan fenomena tertentu secara terperinci. Penelitian ini biasanya tanpa menggunakan hipotesis, yang dirumuskan secara ketat, tetapi ada kalanya menggunakan hipotesis tetapi bukan untuk diuji secara statistik.

Kegiatan penelitian ini dilakukan dengan pendekatan deskriptif kualitatif. Data yang diperoleh akan dideskripsikan secara kualitatif. Pendekatan kualitatif lebih merupakan wujud kata-kata dari pada deretan angka-angka. Data kualitatif yang dihasilkan akan dapat memberikan jawaban hasil penelitian yang dilakukan. Penelitian dilakukan pada objek kampus perguruan tinggi yang belum menerapkan aspek smart campus atau kampus cerdas.

Langkah awal pengumpulan data menggunakan metode studi pustaka. Studi pustaka merupakan metode pengumpulan data yang diarahkan kepada pencarian data dan informasi melalui dokumen-dokumen, baik dokumen tertulis, foto, gambar, maupun dokumen elektronik yang dapat mendukung dalam proses penulisan (Sugiyono, 2005).

Penelitian Penerapan Smart Campus Sebagai Pendukung Kegiatan Pendidikan dalam Tri Dharma Perguruan Tinggi dilakukan dalam kurun waktu satu bulan mulai awal Juni 2018 hingga akhir Juni 2018.

\section{HASIL DAN PEMBAHASAN}

Pendidikan tinggi pada perguruan tinggi adalah jenjang pendidikan setelah pendidikan menengah yang mencakup program diploma, program sarjana, program magister, program doktor, dan program profesi, serta program spesialis, yang diselenggarakan oleh perguruan tinggi berdasarkan kebudayaan Bangsa Indonesia (Sutrisna, 2017). Pendidikan pada perguruan tinggi menjadi salah satu aspek dalam menghasilkan tenaga kerja terampil dan tenaga ahli yang berkarakter serta inovasi yang memiliki daya saing dalam dan luar negeri. Persaingan lulusan yang semakin ketat antar negara dalam era globalisasi membutuhkan sarana dan prasarana pendidikan yang semakin modern dan maju. Pendidikan merupakan salah satu aspek dari Tri Dharma Perguruan Tinggi selain mampu bersaing juga diharapkan mampu menjawab tantangan yang dituntut oleh masyarakat. Sebagai masyarakat ilmiah, lulusan perguruan tinggi diharapkan berperan aktif mampu membantu memecahkan masalah di masyarakat dengan menghasilkan ilmu siap pakai.

Pemangku kepentingan pada perguruan tinggi meliputi staf administrasi, dosen dan tenaga pendidik serta mahasiswa. Menilik dari periode tahun kelahiran, saat ini tahun 2018 kampus dipenuhi oleh kebanyakan mahasiswa yang berumur sekitar 18 - 19 tahun. Mahasiswa tersebut lahir pada periode antara tahun 1999 2000. Tahun kelahiran pada periode tersebut masuk dalam kelompok Generasi Net, yaitu lahir antara tahun 1995 - 2009. Generasi Net ini juga dikenal dengan sebutan generasi Z. Generasi ini memiliki perilaku dan kepribadian yang berbeda dengan generasi sebelumnya. Karakteristik umum generasi $\mathrm{Z}$ ini antara lain, fasih teknologi, sikap keterbukaan dalam berpendapat dan multi tasking. Generasi $\mathrm{Z}$ terbiasa dengan teknologi, akrab dengan teknologi internet, wifi dan smartphone (Tapscott, 2009).

Karakteristik mahasiswa generasi $\mathrm{Z}$ yang sudah siap untuk menerima perubahan lebih modern dalam penyelenggaraan proses belajar mengajar di perguruan tinggi menjadi semakin terbuka. Menurut

Smart campus atau kampus cerdas mendukung penerapan teknologi memungkinkan peningkatan efisiensi dan efektifitas penyelenggaraan proses belajar mengajar. Teknologi smart campus di perguruan tinggi yang mungkin diterapkan misalnya, penerapan sensor kehadiran mahasiswa dan dosen, tersedianya jaringan wifi di dalam kampus, manajemen pendingin dan penerangan ruangan otomatis, aplikasi mobile pendukung perkuliahan, jaringan cctv dan surveillance, sensor parking, collaborative boards, interactive projectors, pembelajaran online (e-learning), penerapan artificial intellegent, digital classroom, sistem informasi akademik dan web conferencing. Seluruh teknologi smart campus yang diterapkan diharapkan dapat mendukung pembelajaran 
dimana saja dan kapan saja karena materi perkuliahan dapat diakses dari banyak saluran dengan berbagai macam konten. Penerapan teknologi smart campus dapat dilakukan secara modular dan bertahap. Penerapan teknologi smart campus secara keseluruhan akan banyak menghabiskan dana. Beberapa teknologi smart campus yang dapat diterapkan adalah:

1) Jaringan $\mathrm{WiFi}$

Jaringan WiFi adalah nama populer untuk teknologi jaringan nirkabel dengan menggunakan gelombang radio yang dapat menyediakan koneksi internet berkecepatan tinggi hingga 54 Mbps. Berdasarkan dokumen Badan Akreditasi Nasional (BAN), sistem informasi yang disediakan bagi mahasiswa dan dosen untuk mengakses sumber informasi dapat berupa website institusi, fasilitas internet, jaringan lokal dan jaringan nirkabel. Perbandingan antara jumlah mahasiswa dan kebutuhan bandwidth internet yang memadai adalah sebesar 0,75 KBPM (Kapasistas Bandwidth Per Mahasiswa) atau 0,75 Kbps per mahasiswa. Jadi misalnya, terdapat 80.000 mahasiswa aktif, maka untuk penerapan smart campus yang memadai, dibutuhkan total $0.75 \mathrm{Kbps}$ x $80.000=60.000$ Kbps setara 60 Mbps (Suhardjanto, 2017). Dengan semakin murahnya harga bandwidth untuk koneksi ke internet, bukan tidak mungkin lebar pita bandwidth yang disediakan oleh kampus bisa belipat kali dari ketentuan BAN tersebut. Misalnya pada Univesitas Ahmad Dahlan, Yogyakarta, yang menyediakan bandwidth internet sebesar 32,8 Kbps per mahasiswa. Kapasitas bandwidth internet tersebut sekitar 43 kali lebih tinggi dari standar BAN.

2) Aplikasi Mobile e-Learning

Banyak kampus telah menerapkan elearning atau pembelajaran melalui media elektronik, biasanya mengacu pada media pembelajaran melalui internet atau online learning. Banyak aplikasi Learning Management System (LMS) yang mendukung pembelajaran berbasis e-learning tersebut. Salah satu yang banyak diimplementasikan adalah LMS Moodle. Moodle merupakan aplikasi berbasis web yang populer dan banyak digunakan untuk menerapkan e-learning berstandar internasional. Moodle berlisensi open source dan didesain untuk membantu pengajar menerapkan pembelajaran atau materi secara efektif melalui media online. Mahasiswa mudah mengunakan dengan mengakses melalui smartphone, tablet dan laptop (Moodle, 2018). Sejak tahun 2010,
Google menyatakan bahwa akan semakin banyak orang mengakses internet menggunakan smartphone dibandingkan menggunakan laptop atau PC desktop. Hal ini didasari dari perkembangan kebiasaan orang mengakses internet menggunakan smartphone, misalnya dari $2 / 3$ pengguna smartphone, sebanyak $68 \%$ nya yang tergolong generasi milenial akan memeriksa smartphone 15 menit setelah bangun tidur. Golongan mahasiswa kebanyakan termasuk dalam generasi $\mathrm{Y}$ atau milenial memiliki kebiasaan $87 \%$ dari mereka selalu membawa smartphone sepanjang hari. Generasi $\mathrm{Y}$ juga memiliki kebiasaan melihat smartphone sebanyak 150 kali per hari (Google, 2017) Data tersebut disediakan Google untuk memperlihatkan betapa pentingnya smartphone saaat ini sehingga tidak dapat terlepas dari kehidupan sehari-hari. Demikian juga dengan proses pendidikan melalui teknologi smart campus akan mudah penetrasi dalam proses pembelajaran jika nyaman diakses menggunakan smartphone atau secara mobile.

Moodle menyediakan aplikasi mobile untuk smartphone Android yang dapat digunakan untuk mengakses website moodle agar tampilan lebih nyaman saat digunakan secara mobile.

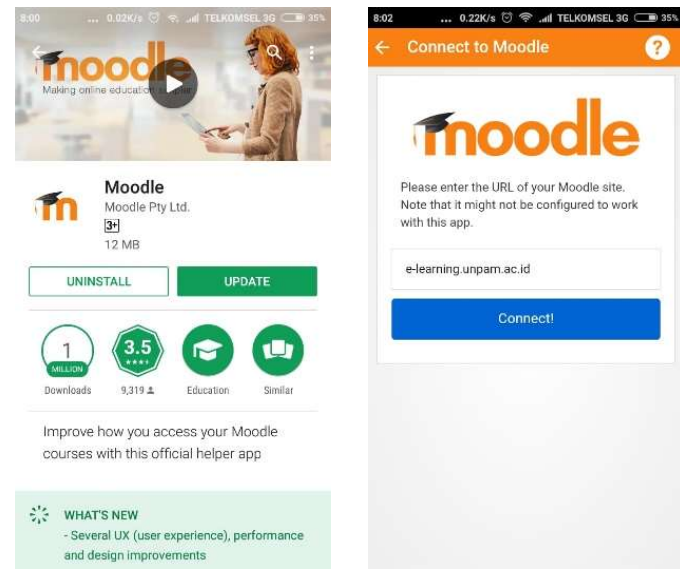

Gambar. 1. Aplikasi mobile Moodle dan cara koneksi ke satu website e-learning.

Tampilan pada aplikasi mobile smartphone lebih mudah dinavigasi. Tampilan website moodle di smartphone bukan merupakan tampilan dari RWD (responsive web design). Berikut adalah contoh dari tampilan website elearning menggunakan aplikasi mobile: 

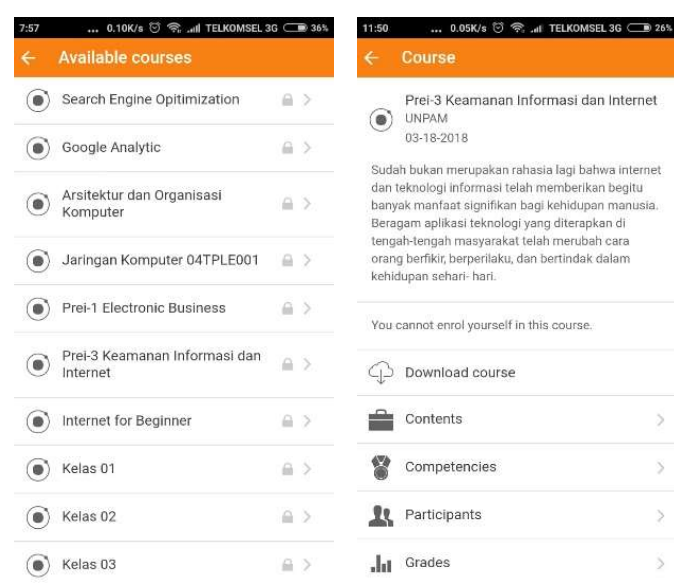

Gambar. 2. Tampilan daftar couses e-learning dan salah satu courses.

3) Aplikasi Web Conference

Bagaimana menyelenggarakan praktikum menggunakan aplikasi pembelajaran online seperti Moodle? Moodle menyediakan fitur BigBlueButton untuk menjalankan fasilitas video conference berbasis web atau lebih dikenal dengan nama web conferencing system. Menggunakan web conference memungkinkan mahasiswa untuk presentasi tugas atau mengikuti demo yang dilakukan oleh dosen. Berikut contoh saat mahasiswa presentasi secara online menggunakan fitur web conferencing system, BigBlueButton.

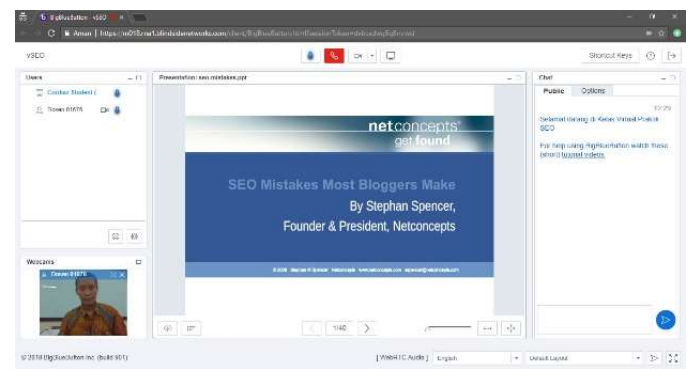

Gambar. 3. Aplikasi web conferencing system BigBlueButton pada Moodle.

Aplikasi web conferencing system merupakan aplikasi berlisensi open source. Aplikasi web conferencing memungkinkan dosen berbagi video, slide, chat dan screen desktop. Banyaknya perangkan ini memungkinan web conferencing seperti di ruang kelas konvensional. Proses pembelajaran bisa efisien dengan menerapkan sistem web conferencing ini (BigBlueButton).

\section{KESIMPULAN}

Peneraapan teknologi smart campus berupa jaringan wifi, aplikasi mobile e-learning dan aplikasi web conference dalam penyelenggraan pendidikan proses belajar mengajar diharapakan dapat membentuk lingkungan kampus yang interaktif, fleksible dan efisien dalam penggunaan dana.

\section{DAFTAR PUSTAKA}

Basuki, Sulistyo. 2010. Metode Penelitian. Penaku. Jakarta.

BigBlueButton. 2018. https://bigbluebutton. org/teachers/. Diakses tanggal 30 Juni 2018

Darma Putra, IKG. 2017. Smart Campus. https://konsultasi.unud.ac.id/articles/smartcampus. Diakses tanggal 10 Juni 2018.

Google. $2017.2 h t$ tps://think.storage googleapis.com/images/micromoments-guideto-winning-shift-to-mobile-download.pdf Diakses tanggal 25 Juni 2018.

Moodle. 2018. https://docs.moodle.org/35/ en/Features. Diakses tanggal 20 Juni 2018.

Rusidi. 1991. Bahan Perkuliahan Metodologi Penelitian. Pascasarjana Universitas Padjadjaran. Bandung.

Sugiyono. 2005. Metode Penelitian Bisnis. Alfabeta, Bandung.

Suhardjanto, Djoko. 2017. AIPT BAN PT. Presentasi. Solo.

Suryana. 2010. Metodologi Penelitian, Model Praktis Penelitian Kuantitatif dan Kualitatif. Universitas Pendidikan Indonesia. Bandung.

Tapscott, Don. 2009. Grown Up Digital, yang Muda yang Mengubah Dunia. PT Gramedia Pustaka Utama. Jakarta.

Wibawa, Sutrisna. 2017. Tri Dharma Perguruan Tinggi (Pendidikan dan Pengabdian Kepada Masyarakat). Rapat Perencanaan Pengawasan Proses Bisnis Perguruan Tinggi Negeri Yogyakarta. 29 Maret 2017, Yogyakarta 